\title{
Does the Use of Nursing-Care Services Reduce the Information about Dementia Patients Provided by Their Caregivers?
}

\author{
Yu Nakamura ${ }^{a}$ Akira Homma ${ }^{b}$

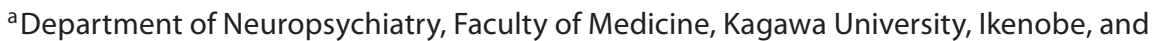 \\ ${ }^{b}$ Center for Dementia Care Research in Tokyo, Tokyo, Japan
}

\section{Key Words}

Alzheimer's disease $\cdot$ Caregivers $\cdot \mathrm{CIBIC}$-plus $\cdot$ Dementia $\cdot$ Nursing-care burden $\cdot$ Nursing-care insurance program $\cdot$ Nursing-care service

\begin{abstract}
Background: The rate of use of nursing-care services has been increasing dramatically in recent years with the upgrading of the public long-term care insurance system in Japan. We addressed how the increased use of the nursing-care services might affect the information on the patients provided by their caregivers. Methods: A questionnaire survey of 531 family caregivers caring for dementia patients at home was carried out to investigate how the use of these services might affect the information about the patients provided by the caregivers. The survey revealed that the use of the nursing-care services reduced the burden (quality, quantity, time of nursing care, and feeling) on the caregivers. Results: According to the observation provided by the caregivers, the patients' behaviors and activities at home tended to decrease. These results indicated that the use of the nursing-care services resulted in a reduction in the opportunity for and the time spent on observation of the patients by the caregivers, making it more difficult for the caregiver to provide an appropriate assessment of the patient's condition. Conclusions: We discussed the impact of the use of the nursing-care services on the Clinician's Interview-Based Impression of Change plus (CIBIC-plus) rating. Due to the reduction in the time spent on nursing care and in the opportunity for observation of the patient's activities of daily living by the caregiver resulting from the use of the nursing-care services, it is difficult to obtain an accurate picture of the patient's clinical condition using the CIBIC-plus, probably leading to an inappropriate CIBIC-plus rating.

Copyright $\odot 2011$ S. Karger AG, Basel
\end{abstract}




\section{Introduction}

In a report published by the Ministry of Health, Labor and Welfare in Japan, nursingcare services have been upgraded and expanded since the introduction of the public longterm care insurance system (April 2000), thus leading to a dramatic increase in the number of users of these nursing-care services. Under these circumstances, it would be useful to study how the increasing use of the nursing-care services might affect the nursing care of dementia patients provided by the caregiver(s) in the family. To investigate the changes in the nursing care provided by the home caregiver who is assisted by nursing-care services established by the public nursing-care insurance program, questionnaires were issued to family caregivers of patients with dementia. The target subjects were restricted to those who employed at least one of the following nursing-care services: ambulatory nursing-care services (day care: DC), and 1-day nursing-care service mainly for rehabilitation at facilities built on the property of such institutions as healthcare facilities for the elderly, hospitals and clinics. The services included assistance for taking a bath, eating, and toileting; day service [(DS): 1-day nursing-care services including assistance for example for taking a bath, eating and toileting, other activities of daily living (ADL) and behavioral training], home-visit nursing-care services (home nursing care, domiciliary care, home-visit rehabilitation, and bath services provided by nursing-care workers), and short-stay personal care.

In clinical trials of drugs for Alzheimer's disease (AD), both the cognitive subscale of the AD Assessment Scale and the global assessment scale Clinician's Interview-Based Impression of Change plus (CIBIC-plus) [1] are now widely used to determine the primary endpoints. The original CIBIC was a rating scale that was based solely on patient interviews. However, because AD patients often have cognitive dysfunctions, it is difficult to accurately evaluate the information obtained from the patients alone to accurately assess patients' ADL and abnormal behaviors. In addition, it is almost impossible to assess the patients' clinical features at times other than during the interview. Under these circumstances, the CIBICplus was developed for the global clinical rating, which is based not only on information obtained by patient interview, but also on that provided about the patient by the primary caregiver. This is why the CIBIC-plus rating depends considerably on the patient information provided by the caregivers, and why it is crucial to obtain accurate and abundant information from the primary caregiver [2]. Based on the results of the present survey, we discuss how the changes in the status of nursing care provided at home by the family caregiver with the use of the nursing-care services might affect the CIBIC-plus rating of AD patients in Japan from the viewpoint of the investigators of clinical studies.

\section{Materials and Methods}

\section{Materials and Survey Procedures}

A preliminary questionnaire survey of monitors (preliminary survey; 12,462 people) registered at a research company was performed to investigate family members suffering from dementia (but who could walk independently) using nursing-care services (ambulatory nursing-care services, home-visit nursing-care services, or short-stay personal care) for the full-scale questionnaire survey.

Of the 603 monitors to whom the full-scale questionnaire survey form was finally mailed, valid responses were obtained from 531 monitors (valid response rate: $88.1 \%$ ). The survey was conducted from November to December 2009. 
Survey Issues

The questionnaire contained items pertaining to such issues as age and sex of the patient and of his/her family members who were primarily in charge of the nursing care of the patient), use of nursing-care services (e.g. type, frequency and duration of the nursing-care services provided), changes in the nursing-care burden (quality, quantity, and time) posed on the family members, and in the perception of these changes by the caregiver, and the changes in the patient's activities and behaviors with the use of the nursing-care services (table 1).

\section{Classification and Analysis of Questionnaire Survey Results}

The questionnaire survey results were classified and analyzed according to the following procedures.

- Number of days and the length of time spent for using ambulatory nursing-care services per week were expressed as the total use of DC and DS.

- Number of days and the length of time spent for using home-visit nursing-care services per week were expressed as the total use of home nursing care, domiciliary care, homevisit rehabilitation, and bath services provided by nursing-care workers.

- Number of days of use of the nursing-care services per week was expressed as the total use of DC, DS, home nursing care, domiciliary care, home-visit rehabilitation, and bath services provided by the nursing-care workers.

- Time spent for nursing-care services per week was expressed as the total use of DC, DS, home nursing care, domiciliary care, and home-visit rehabilitation provided by the nursing-care workers.

- Numbers of baths and meals at home (with no use of nursing-care services) were classified as 'at home', and the total number of baths and meals during the use of DC, DS, short-stay personal care, or at home (during the use of nursing-care services) were classified as 'during nursing-care services'.

- Unclear or no answers were excluded from the data set of this analysis.

\section{Ethical Considerations}

Informed consent was obtained from all of the enrolled monitors after providing an adequate explanation to them about issues concerning handling of private information, in conformity with the ethical provisions of the research company. Information that would have enabled the identification of any individual enrolled in the study was not included in the survey data. Personal information was thoroughly protected according to the Private Information Protection Law.

\section{Results}

\section{Background Factors of the Patients and Their Main Caregivers}

Of the enrolled patients, $25.6 \%$ were males and $74.4 \%$ were females. The mean age of the patients was $84.1 \pm 7.1$ years. Patients were most frequently certified as falling under the ' 1 st degree of care necessity' (25.0\%), '2nd degree of care necessity' (31.0\%), or '3rd degree of care necessity' (25.9\%). Concerning the use of the nursing-care services, $92.6 \%$ of patients used ambulatory nursing-care services (DC/DS), showing that the utilization rate of DC/DS was much higher compared with that of the home-visit nursing-care services (18.1\%) or shortstay personal care (43.4\%; table 2).

As for the main caregiver(s), the percentage of female caregivers was higher (89.0\%) compared with that of male caregivers (11.0\%). The mean age of the main caregiver(s) was 59.0 
Table 1. Questionnaire

\begin{tabular}{|c|c|}
\hline Questions & Answers \\
\hline 1 Patient's sex & $\begin{array}{l}1 \text { Male } \\
2 \text { Female }\end{array}$ \\
\hline 2 Patient's age & (Describe specific age) \\
\hline 3 'Eligibility of long-term care insurance' and its degree & $\begin{array}{l}1 \mathrm{Yes} \rightarrow \text { degree } \\
2 \mathrm{No}\end{array}$ \\
\hline $\begin{array}{l}4 \text { Use of DC } \rightarrow \text { If yes, describe the frequency (average days per week } \\
\text { and hours per day) }\end{array}$ & $\begin{array}{l}1 \mathrm{Yes} \rightarrow \text { frequency } \\
2 \mathrm{No}\end{array}$ \\
\hline $\begin{array}{l}5 \text { Use of DS } \rightarrow \text { If yes, describe the frequency (average days per week } \\
\text { and hours per day) }\end{array}$ & $\begin{array}{l}1 \text { Yes } \rightarrow \text { frequency } \\
2 \text { No }\end{array}$ \\
\hline $\begin{array}{l}\text { Use of in-home services } \rightarrow \text { If yes, specify the service ('nursing care', } \\
\text { 'domiciliary care', 'home-visit rehabilitation', and 'home bath service') } \\
\text { and the frequency (average days per week and hours per day) }\end{array}$ & $\begin{array}{l}1 \text { Yes } \rightarrow \text { descriptions and frequency } \\
2 \text { No }\end{array}$ \\
\hline $\begin{array}{l}7 \text { Use of short-stay personal care } \rightarrow \text { If yes, describe the frequency } \\
\text { (average days per month) }\end{array}$ & $\begin{array}{l}1 \mathrm{Yes} \rightarrow \text { frequency } \\
2 \mathrm{No}\end{array}$ \\
\hline 8 Ability of walking independently (including use of a cane) & $\begin{array}{l}1 \text { Ambulant } \\
2 \text { Not ambulant }\end{array}$ \\
\hline 9 ADL and care which the patient needs support in (choose all that apply) & $\begin{array}{l}1 \text { Taking a bath } \\
2 \text { Toileting } \\
3 \text { Eating } \\
4 \text { Wearing or removing clothes and } \\
\text { shoes } \\
5 \text { Grooming and appearance } \\
6 \text { Brushing teeth } \\
7 \text { Taking medicine } \\
8 \text { Watching the patient at home } \\
9 \text { Watching the patient outside } \\
10 \text { Nothing at all }\end{array}$ \\
\hline $\begin{array}{l}10 \text { Number of days for taking a bath per week and its start [DC, DS, short-stay } \\
\text { personal care, at home (with or without care service)] }\end{array}$ & (Describe number) \\
\hline $\begin{array}{l}11 \text { Number of days for eating breakfast/lunch/dinner per week [DC, DS, } \\
\text { short-stay personal care, at home (with or without nursing care service)] }\end{array}$ & (Describe number) \\
\hline $\begin{array}{l}12 \text { Change in burden (quality, quantity, and time) on family using care service } \\
\text { (for each point in question } 9 \text {, but choose one answer per point) }\end{array}$ & $\begin{array}{l}1 \text { Increased } \\
2 \text { No change } \\
3 \text { Decreased } \\
4 \text { Mostly disappeared }\end{array}$ \\
\hline 13 Change in the feeling of burden of family by using care service (choose one) & $\begin{array}{l}1 \text { Increased } \\
2 \text { No change } \\
3 \text { Decreased } \\
4 \text { Mostly disappeared }\end{array}$ \\
\hline 14 Change in burden (quality, quantity, and time) on the family using care service & (Free writing) \\
\hline $\begin{array}{l}15 \text { Change in the frequency of the following behaviors or activities of the patient } \\
\text { at home: (1) housework, (2) using a telephone, (3) conversation with family } \\
\text { members, (4) watching TV, (5) hobbies, and (6) walking (choose one) }\end{array}$ & $\begin{array}{l}1 \text { Increased } \\
2 \text { No change } \\
3 \text { Decreased } \\
4 \text { Mostly disappeared }\end{array}$ \\
\hline 16 Primary caregiver's sex & $\begin{array}{l}1 \text { Male } \\
2 \text { Female }\end{array}$ \\
\hline 17 Primary caregiver's age & (Describe specific age) \\
\hline
\end{tabular}


Table 1 (continued)

\begin{tabular}{lll}
\hline Questions & Answers \\
\hline 18 Relationship with the patient (choose one) & 1 Spouse \\
& 2 Son \\
& 3 Daughter \\
& 4 Son's wife \\
& 5 Daughter's husband \\
& 6 Grandchild \\
& 7 Brother/sister \\
& 8 Mother \\
\hline 19 Living together with the patient and primary caregiver $\rightarrow$ If not, describe & 9 Father \\
frequency of visiting the patient per week & 10 Other $(\ldots)$ \\
\hline 20 Secondary caregivers $\rightarrow$ If yes, describe relationship with the patient and & 1 Living together \\
numbers & 2 Not living together $\rightarrow$ frequency \\
& 1 No \\
& 2 Yes \\
& 1 Spouse \\
& 2 Son $(\ldots)$ \\
& 3 Daughter $(\ldots)$ \\
& 4 Son's wife $(\ldots)$ \\
& 5 Daughter's husband $(\ldots)$
\end{tabular}

\pm 11.1 years. Patients were most frequently cared for by the son's wife (39.2\%) or the daughter (33.1\%); $18.9 \%$ of the patients were cared for by the spouses, i.e. $13.8 \%$ by the wife and $5.1 \%$ by the husband. The main caregiver(s) lived with the patient in $95.8 \%$ of the cases. In $74.5 \%$ of the families, apart from the main caregiver, other caregivers were also available, showing that nursing-care activities were shared among family members.

The number of days and the length of time spent using the nursing-care services per week were surveyed (data concerning short-stay personal care, which were frequently used on an irregular basis, were not included in the total number of days and the total time spent for using the nursing-care services per week; in addition, the length of time spent using the home-visit bathing services was not investigated and not included in the data for the time spent using the nursing-care services). Patients used the nursing-care services a total of 3.5 \pm 1.8 days per week on average; they used DC/DS on $3.1 \pm 1.8$ days/week and home-visit nursing-care services on $0.6 \pm 1.6$ days/week. They used short-stay personal care a total of $2.4 \pm 4.3$ days per week on average. The mean total length of time spent using the nursingcare services was $21.6 \pm 13.5 \mathrm{~h} /$ week; patients used DC/DS $21.0 \pm 14.0 \mathrm{~h} /$ week and homevisit nursing-care services $1.1 \pm 4.2 \mathrm{~h}$ /week. Both the total number of days and the total number of hours using the services were larger for DC/DS than for the home-visit nursingcare services.

Changes in the Nursing-Care Burden (Quality, Quantity, and Time) on the Family

Caregivers by the Use of the Nursing-Care Services

The necessity of using the nursing-care services was surveyed for nine ADL items (taking a bath, toileting, eating, wearing or removing clothes and shoes, grooming and appear- 
Table 2. Patient demographics

\begin{tabular}{|c|c|c|c|}
\hline & & $\mathrm{n}$ & $\%$ \\
\hline \multirow{2}{*}{$\operatorname{Sex}(n=531)$} & Males & 136 & 25.6 \\
\hline & Females & 395 & 74.4 \\
\hline \multirow[t]{4}{*}{ Age $(n=529)$} & $<65$ years & 3 & 0.6 \\
\hline & $65-75$ years & 45 & 8.5 \\
\hline & $75-85$ years & 231 & 43.7 \\
\hline & $>85$ years & 250 & 47.3 \\
\hline \multirow[t]{8}{*}{ Degree of 'care necessity' $(\mathrm{n}=529)$} & No need & 8 & 1.5 \\
\hline & Need support-1 & 12 & 2.3 \\
\hline & Need support-2 & 22 & 4.2 \\
\hline & Need care-1 & 132 & 25.0 \\
\hline & Need care-2 & 164 & 31.0 \\
\hline & Need care- 3 & 137 & 25.9 \\
\hline & Need care- 4 & 49 & 9.3 \\
\hline & Need care-5 & 5 & 0.9 \\
\hline \multirow[t]{2}{*}{ Use of ambulatory DC/DS $(n=529)$} & No & 39 & 7.4 \\
\hline & Yes & 490 & 92.6 \\
\hline \multirow[t]{2}{*}{ Use of DC $(n=489)$} & No & 323 & 66.1 \\
\hline & Yes & 166 & 33.9 \\
\hline \multirow[t]{2}{*}{ Use of DS $(n=513)$} & No & 96 & 18.7 \\
\hline & Yes & 417 & 81.3 \\
\hline \multirow[t]{2}{*}{ Use of in-home service $(n=504)$} & No & 413 & 81.9 \\
\hline & Yes & 91 & 18.1 \\
\hline \multirow[t]{2}{*}{ Nursing care $(\mathrm{n}=504)$} & No & 434 & 86.1 \\
\hline & Yes & 70 & 13.9 \\
\hline \multirow[t]{2}{*}{ Domiciliary care $(\mathrm{n}=504)$} & No & 471 & 93.5 \\
\hline & Yes & 33 & 6.5 \\
\hline \multirow[t]{2}{*}{ Home-visit rehabilitation $(\mathrm{n}=504)$} & No & 482 & 95.6 \\
\hline & Yes & 22 & 4.4 \\
\hline \multirow[t]{2}{*}{ Home bath service $(n=504)$} & No & 477 & 94.6 \\
\hline & Yes & 27 & 5.4 \\
\hline \multirow[t]{2}{*}{ Short-stay personal care $(\mathrm{n}=505)$} & No & 286 & 56.6 \\
\hline & Yes & 219 & 43.4 \\
\hline
\end{tabular}

Mean age \pm SD was $84.1 \pm 7.1$. Unclear or missing answers are excluded from the analysis.

ance, brushing of teeth, taking medicines, watching the patients at home, and watching the patients outside). The percentage of patients who needed nursing care was particularly high for 'taking medicines' (84.3\%), 'watching the patients outside' (83.4\%), 'taking a bath' (74.3\%), and 'grooming and appearance' (66.2\%; fig. 1$)$.

Changes in the nursing-care burden (quality, quantity, and time) on the family caregiver by the use of the nursing-care services were surveyed for the above nine items only among patients who needed nursing care for each item. The nursing-care burden 'almost disappeared' or 'decreased' in a high percentage of caregivers for 'taking a bath' (79.9\%), 'eating' (63.6\%), 'watching the patients at home' (56.0\%), 'toileting' (51.9\%), 'watching the patients outside' (34.3\%), 'brushing of teeth' (33.3\%), 'wearing or removing clothes and shoes' (32.2\%), 'grooming and appearance' (24.3\%), and 'taking medicine' (18.7\%). The percentage of caregivers in whom the burden 'almost disappeared' was particularly high (42.5\%) for 'taking a bath' (fig. 2). 


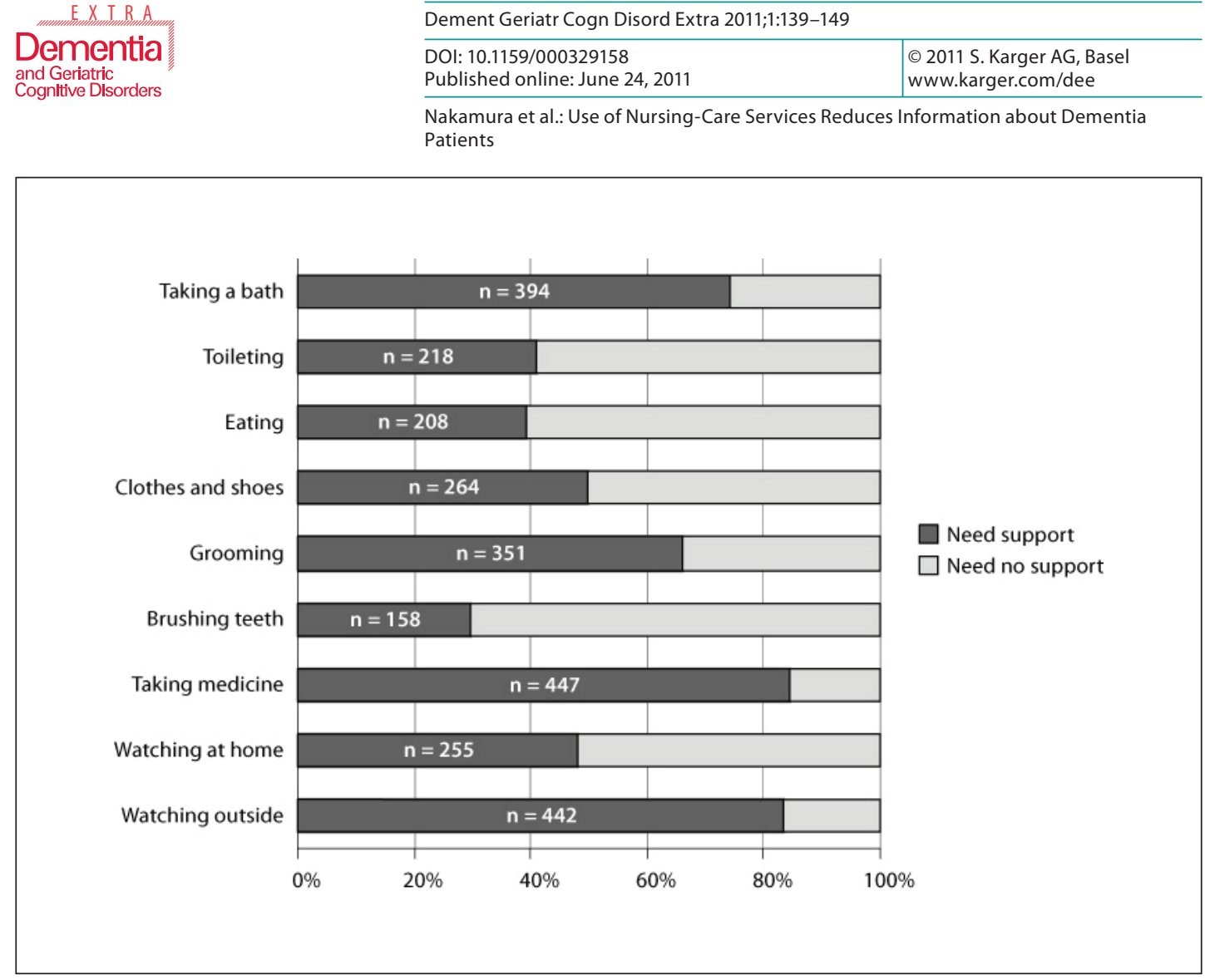

Fig. 1. Percentage of patients who need support in activities. $\mathrm{n}=530$.

Number of Baths and Meals with the Use of Nursing-Care Services

Generally, it is presumed that patients who use nursing-care services also frequently receive bathing and meal services. The weekly percentage of patients taking a bath while receiving nursing-care services was $70.4 \%$. Patients took a bath most frequently during DC/DS; $75.9 \%$ of the entire patient population bathed at least once a week during the DC/DS, $22.8 \%$ during a short-stay personal care, and $8.7 \%$ while at home (using a nursingcare service). In addition, more than half $(55.7 \%)$ of the patients did not take a bath at home.

Comparison of the mean weekly number of meals (breakfast, lunch, and dinner) taken at home and while using nursing-care services, patients had breakfast 5.16 times at home and 1.21 times while receiving nursing-care services, lunch 3.16 and 3.76 times, and dinner 5.17 and 1.30 times, respectively, showing that they particularly ate lunch more frequently while receiving nursing-care services. The weekly percentage of lunches taken at home was decreased compared to the $58 \%$ while receiving nursing-care services. Of the entire patient population, $90.3 \%$ ate lunch at least once during DC/DS, $25.3 \%$ during short-stay personal care, and $76.2 \%$ at home (while using a nursing-care service), showing that, as in the case of bathing, patients ate lunch most frequently while receiving DC/DS.

Changes in the Caregiver's Perception Concerning the Changes in the Nursing-Care

Burden with the Use of Nursing-Care Services

Regarding changes in the caregiver's perception concerning the changes in the care burden with the use of nursing-care services, $76.8 \%$ of the caregivers felt that the nursingcare burden 'decreased' or 'almost disappeared' with the use of the nursing-care services (fig. 3). 


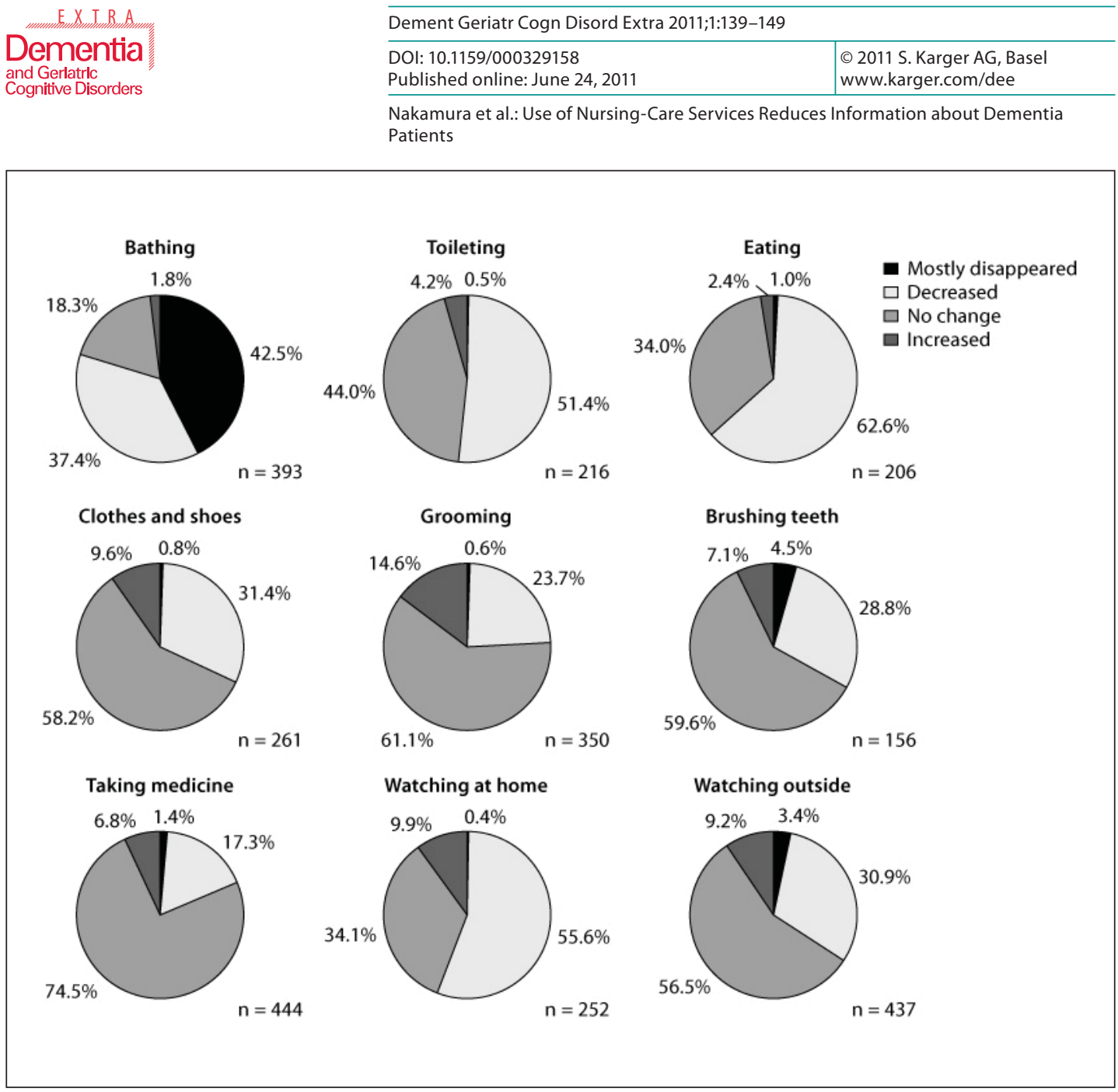

Fig. 2. Change in the burden (quality, quantity, and time) on family caregivers by using care service. Only patients who need support in the respective activity were assessed.

Fig. 3. Change in the family's feeling of burden using nursing-care services.

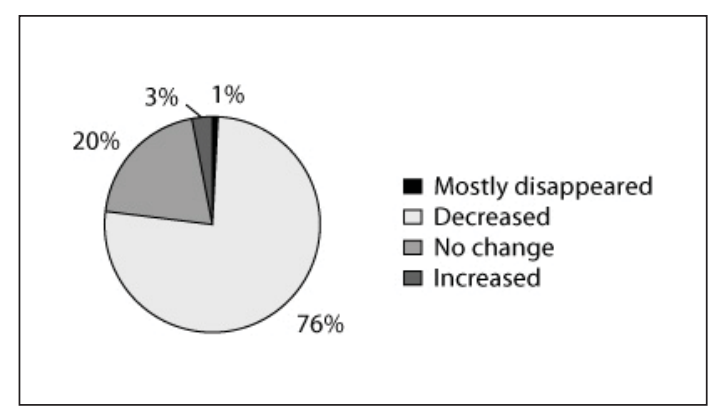

Changes in Patients' Activities and Behaviors upon the Use of Nursing-Care Services

Changes in the patients' activities and behaviors with the use of nursing-care services were surveyed according to six items of the ADL and behaviors (housework, using a telephone, conversation with family members, watching TV, hobbies, and taking a walk). 'No change' was the most common for all of these items. The percentage of responses of 'almost disappeared' or 'decreased' was relatively higher for 'housework' (38.6\%), 'taking a walk' (37.9\%), 'hobbies' (37.5\%), and 'using a telephone' (36.0\%; fig. 4). 


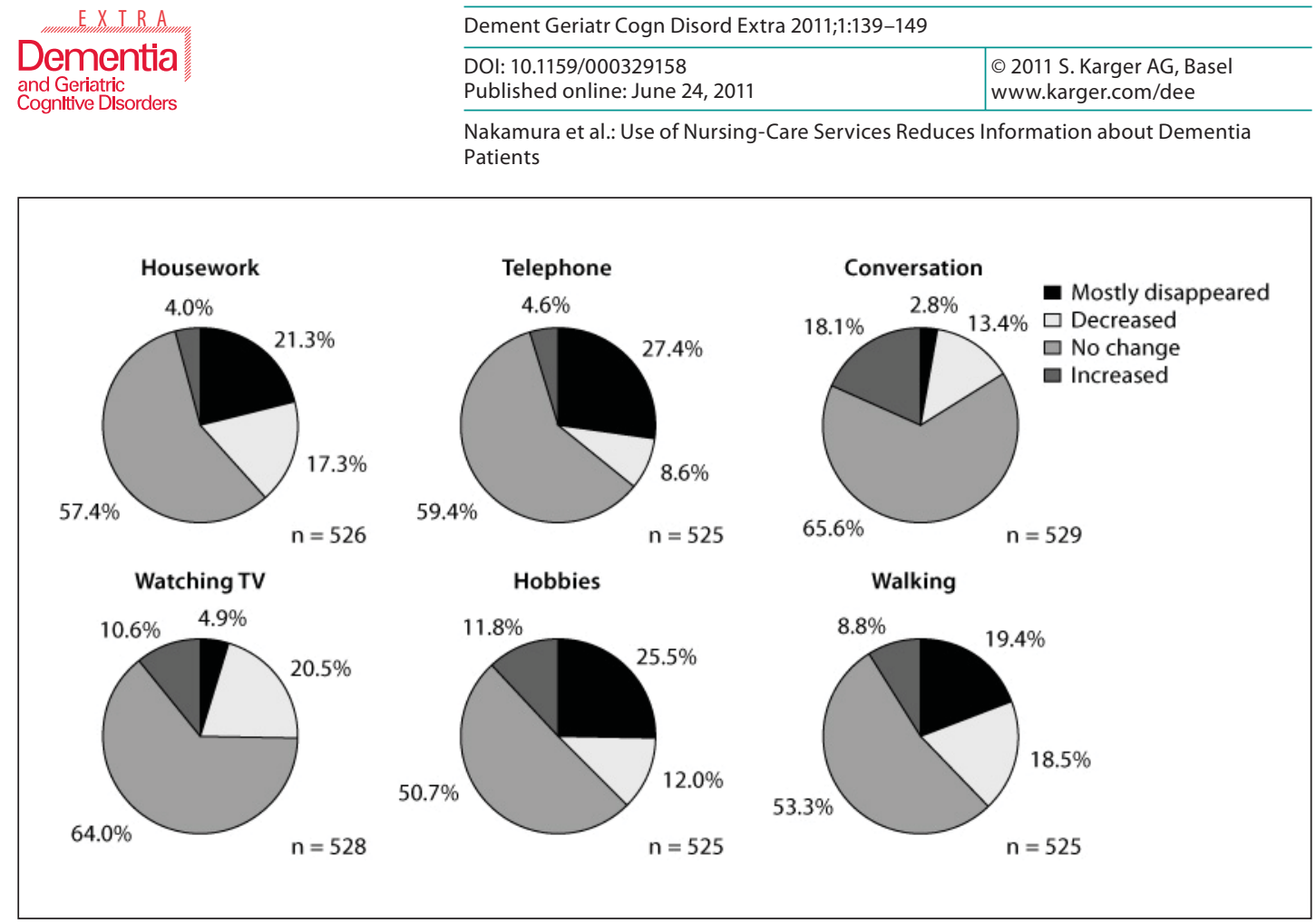

Fig. 4. Change in the frequency of patient activities.

\section{Discussion}

Changes in the Nursing-Care Burden on the Family Caregiver with the Use of the Nursing-Care Services

A questionnaire survey was conducted of family caregivers of dementia patients, who were cared for at home and also used nursing-care services, in order to investigate the changes in the nursing care provided at home with the use of such nursing-care services.

The survey showed that caregivers frequently felt that their nursing-care burden (quality, quantity, and time) was reduced due to the use of the nursing-care services, especially for such items as 'taking a bath', 'eating', 'watching the patients at home', 'toileting', 'watching the patients outside', 'brushing of teeth', and 'wearing or removing clothes and shoes'. Actually, there were many patients who had already taken a bath and eaten meals during the time spent using the nursing-care services, resulting in a reduction in the time needed for nursing and observation by the home caregiver, thus reducing his/her burden. There were also many cases in which the patient's activities and behaviors at home were reduced with the use of nursing-care services, in relation to such issues as housework, taking a walk, hobbies, and using a telephone. These results indicated that both the opportunities for and time spent in observation of the patients by the primary caregiver(s) at home were reduced.

These results confirmed that in Japan there were changes in the nursing-care received by dementia patients by the primary caregiver(s) at home with the use of the nursing-care services based on the public long-term care insurance system. These changes included a reduction in the nursing-care burden posed on the caregivers and also a decrease in the patient's activities and behaviors at home, indicating that the use of the nursing-care services often resulted in a reduction in the opportunity for and time spent in observing the patient by the caregiver at home.

It may be useful for an appropriate survey of the nursing-care burden and other relevant issues to compare the survey data obtained before and after the start of use of the nursing- 
care services in individual patients, or to examine these data in comparison with those from patients who did not use the nursing-care services. In the present survey, considering its feasibility, the authors took every effort to avoid selection bias of the subjects by taking such measures as inclusion of only 531 eligible people among general monitors who were registered nationwide. Even with these measures, a certain bias might have been introduced because this was a survey that included all monitors who had been registered at a research company. We consider that care should be taken in generalizing the survey results. We now propose to conduct, without involving any research company, surveys of caregivers of outpatients and nursing-care staff members who offer nursing-care services to confirm whether similar tendencies will be observed using different approaches.

\section{Effects of Changes in the Nursing-Care Burden on the Caregiver at Home on the CIBIC-plus Rating}

The rate of use of nursing-care services has been increasing dramatically in recent years with the upgrading of the public long-term care insurance system in Japan. This change would be expected to contribute to the reduction in the nursing-care burden posed on the family caregiver(s) by reducing the time needed for nursing by the caregiver(s). In recent clinical studies conducted in patients with $\mathrm{AD}$, it has been increasingly difficult to detect differences in the global clinical assessment rating that reflects the clinical picture of patients based on the information provided by the caregivers [Pfizer inc. and Medivation: press release March 3, 2010]. These findings imply that the use of nursing-care services may affect the information provided by the caregivers about the patients, with a big impact on the global clinical assessment rating.

In the CIBIC-plus rating, the physician interviews the patient him/herself and his/her caregiver several times, in order to evaluate the changes compared with baseline findings. In our previous studies, the concordance rate of the CIBIC-plus rating was relatively high when specialists conducted the rating based on videos of the interviews, indicating that the contents of the patient interviews are important $[3,4]$. We addressed the issue of how the use of the nursing-care services might affect the CIBIC-plus rating via interview of the caregivers.

The present survey detected multiple questionnaire issues that were associated with the reduction in the time spent for patient care and in the opportunities for observation of the patient's ADL by the caregivers resulting from the use of the nursing-care services. These issues are critical elements in the CIBIC-plus rating. Issues of concern are that the reduced time spent for nursing care and the reduced opportunities for observation of the patient's $\mathrm{ADL}$ by the caregiver at home might result in inaccurate and inadequate information provided by the caregiver about the patient. In addition, the responses to the questionnaire frequently indicated that the overall nursing-care burden posed on the primary caregiver(s) was reduced by the use of the nursing-care services. These changes in the caregiver's burden might possibly affect the observation of the patients by the caregivers and the quality of the information provided about the patient, eventually affecting the accuracy of the CIBIC-plus rating. Our survey indicated that the reduced time spent in nursing care and the reduced opportunities for observation of the patients' ADL by the caregiver due to the use of the nursing-care services might make it difficult for the rater to capture the patient's clinical condition accurately based on the information provided by the caregiver, potentially resulting in inaccurate CIBIC-plus rating.

From the global perspective, a public nursing-care insurance program that comprehensively covers nursing-care of elderly people is hardly available in any other country, including the United States. The above-mentioned impact of the use of nursing-care services on the CIBIC-plus rating may be probably unique to Japan where the public long-term care insurance system has already been implemented. 
The survey also showed that nursing-care was shared by the family members in $74.5 \%$ of the surveyed families of dementia patients. Because it is required for the CIBIC-plus rating that one caregiver is specified as the person providing information about the patient [2], the amount and/or accuracy of the information provided by the specified caregiver may be inadequate when nursing care is shared by family members. Such circumstances might also influence the accuracy of the CIBIC-plus rating.

In conclusion, the use of the nursing-care services may affect the accuracy of the information provided by the caregiver, i.e. an important element in the CIBIC-plus rating. In the field of psychology, when reasoning or making a decision based on certain information, man's decision tends to be made by unintentionally biased processing of the information to avoid any complication in the process, and by roughly focusing on the events that are generally more likely to occur or easier to recall, possibly leading to systematic errors [5-8]. With reference to this theory, when CIBIC-plus rating is based on ambiguous or inadequate information provided by the caregiver, systematic errors are more likely to occur, leading to a higher possibility of the rater making the assessment of 'no change' or 'slightly worse', in relation to the change in the clinical status with disease progression among AD patients over long periods of time (usually the last 24 weeks).

\section{References}

1 Schneider LS, Olin JT: Clinical global impressions in Alzheimer's clinical trials. Int Psychogeriatr 1996;8:277-290.

-2 Boothby H, Mann AH, Barker A: Factors determining interrater agreement with rating global change in dementia: the CIBIC-plus. Int J Geriatr Psychiatry 1995;10:1037-1045.

-3 Homma A, Nakamura Y, Kobune S, Haraguchi H, Kodani N, Takami I, Matsuoka J, Kusunoki T: Reliability study on the Japanese version of the Clinician's Interview-Based Impression of Change. Dement Geriatr Cogn Disord 2006;21:97-103.

-4 Nakamura Y, Homma A, Kobune S, Tachibana Y, Satoh K, Takami I, Nagai S, Sakai M, Fukuta H, Matsuda H, Hashimoto H, Kusunoki T: Reliability study on the Japanese version of the Clinician's Interview-Based Impression of Change. Dement Geriatr Cogn Disord 2006;23:104-115.

-5 Tversky A, Kahneman D: Judgment under uncertainty: heuristics and biases. Science 1974;185:11241131.

-6 Tversky A, Kahneman D: Availability: a heuristic for judging frequency and probability. Cogn Psychol 1973;5:207-232.

7 Reyna VF, Lloyd FJ, Brainerd CJ: Memory, development, and rationality: an integrative theory of judgment and decision making; in Schneider SL, Shanteau J (eds): Emerging Perspectives on Judgment and Decision Research. Cambridge Series on Judgment and Decision Making. Cambridge, Cambridge University Press, 2003, pp 201-215.

8 Reyna VF, Farley F: Risk and rationality in adolescent decision making: implications for theory, practice, and public policy. Psychol Sci Public Interest 2006;7:1-44. 